\title{
Critical Evaluation of Web Sites: An Example in 0steoporosis
}

OBJECTIVE: To describe criteria used to evaluate health-related Web sites and provide three specific examples of evaluating Web sites related to osteoporosis.

DATA SOURCES: Literature references and the World Wide Web.

CONCLUSIONS: The Internet contains a vast amount of medical information. It is vital that health care providers critically evaluate the Web sites from which they choose to base patientcare decisions. The strengths and weaknesses identified in this review of three Web sites support the continued need for careful evaluation in using Web site information regardless of the source.

KEYWORDS: osteoporosis, Internet, drug information, World Wide Web, literature evaluation

J Managed Care Pharm 2000: 316-22

\section{by Bridget M. Olson and Thea M. Garrity}

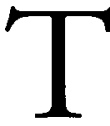
he Internet has become one of the quickest, most easily accessible sources for health information, and its use by consumers and health care providers continues to rise. Currently, there are over 122 million Internet users in the United States.' In 1998, 22 million individuals reported surfing the Web for medical information, and this number is predicted to rise to more 30 million in: 2000. ${ }^{2}$ Although convenient, Internet sources are held only to the standards of the organization producing the information and of the consumer who visits the site.

Specific criteria for evaluating a Web site have been suggested by several authors and a review of published criteria that focused on evaluating health-related information on the World Wide Web was published by Kim et al. in 1999. ${ }^{+}$This review identified 24 Web sites and 5 journal articles with specific criteria by which to evaluate health-related 'Web sites. Based on their review of the criteria, Kim et al. identified 12 key areas that should be examined when evaluating a Web site.

The purpose of this article is to briefly describe these criteria and provide an example of how they can be used. This review will be of interest to managed care pharmacists who wish to learn how to better evaluate Web sites, those who develop or recommend Web pages for consumers, patients, and providers, and those responsible for developing clinical links to their organization's Web page.

Three Web sites about osteoporosis were evaluated. Osteoporosis was chosen because women frequently and actively search for information on menopause and the use of hormone medications. Hormonal therapy is a controversial subject with conflicting published research, and the number of nonhormonal alternatives is rapidly growing. Given the high demand for information on this subject and the controversy surrounding this information, the quality of Web sites on osteoporosis is of particular importance to consumers, providers, and health plans.

\section{Methods}

A search was performed using osteoporosis as the keyword..$^{5.6}$ From this search, three Web sites were chosen for evaluation. They were Web sites from the National Osteoporosis Foundation (NOF), the National Institutes of Health Osteoporosis and Related Bone Diseases National Research Center (NIH ORBD NRC), and the Doctor's Guide to Osteoporosis Information and Resources. ${ }^{7,8,9}$ The NOF site was selected primarily because of its national recognition for research and advocacy in the area of osteoporosis. The NIH 


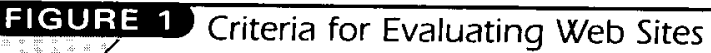

- Content

- Design and aesthetics

- Disclosure of authors, sponsors, developers

- Currency of information

- Authority of source

- Ease of use

- Accessibility and availability

- Links

- Attribution and documentation

- Intended audience

- Contact addresses or feedback mechanism

- User support

Source: Kim $P$, et al. Published criteria for evaluating health related Web sites: review. BMJ 1999; 318: 647-49.

ORBD NRC site was chosen based on the reputation of the NIH for providing quality health information. Finally, the Doctor's Guide site, developed by the P/S/L Consulting Group, was chosen based on its title, suggesting that it is a source for physicians and health care providers to easily access information on osteoporosis.

The 12 criteria that Kim et al. recommend for evaluating Web sites are listed in Figure 1. The following section highlights key issues in each of these 12 areas for the three Web sites evaluated.

\section{Review}

\section{Evaluation 1: National Osteoporosis Foundation (NOF)}

Content of site. This site (www.nof.org) provides information on osteoporosis only. The mission, as stated by the NOF, is to "increase awareness and knowledge about osteoporosis, provide education and training programs for health professionals, advocate for an expanded federal medical research effort, provide information and services to patients and their families, and provide direct financial support for research and research training."

The Web site met its objectives: The NOF provided information throughout the site that was very easy to follow. To increase public awareness, the site offered information in its "Advocacy" section for those who are interested in influencing legislation on health care and specifically osteoporosis. The information provided seemed to be appropriate, and there were no obvious flaws in its quality. In addition, the NOF site offered information on contacting members of Congress.

To promote the education and training of health care providers, the site contained "Clinical Guidelines" for the treatment of osteoporosis, as well as information on upcoming clinical symposia. The information provided in this section remained easy to understand and was slightly more informative than the rest of the site on medication therapy and bone miner- al density (BMD) test procedures. The guideline did not, however, provide any detailed information that might be more useful to physicians and other health care providers. There were no references listed in these sections, therefore the quality and accuracy was not appropriately established.

The NOF site offered information on two research grant opportunities. Adequate information was provided along with the appropriate contact information.

The information and services provided for patients and their families appeared to be of good quality. The site offered medical, social, and recreational support for patients with osteoporosis through support groups, fashion tips, and suggestions for preventing falls in the home. There was a tool to help patients locate a physician who is a member of the NOF Professional Partners Network. The NOF also provided information on the Web site for men with osteoporosis. As with almost all of the information contained in the site, this section contained general, patient-directed information; however, it was the only section to provide references.

The site also contained a "Cutting Edge Report" that provided some interesting information; however, the information contained in this section was not particularly up-to-date. The last update as of March 2000 was from July 1999.

Overall, the content of the site was good. It was not a source for up-to-date news or breakthrough information on osteoporosis. Although the quality and reliability were rated high, the scope and depth of the information provided was weak from a health care provider's perspective. The lack of references throughout the entire site decreases the confidence in any of the specific information, such as percentages and dollar figures cited.

Design and aesthetics. The design of the NOF site was good. It was easy to read and each page was appropriately marked with a clear heading. The appearance of the site was consistent throughout. Pictures and graphics were used to break up the text.

Disclosure of authors, sponsors, developers. The National Osteoporosis Foundation is a nonprofit, voluntary health organization whose mission is described above. Although not stated directly, it appeared that the foundation receives funds through membership fees and direct donations. There were no specific sponsors cited. One of the major drawbacks of the NOF site was the lack of revealed authorship for any of its sections. A list of names and affiliations for the board of trustees, emeritus board, honorary board, scientific advisory board, and the Executive Director for the NOF were provided, but the site did not reveal their specific contributions or whether they review the site. The scientific advisory board did seem to be comprised of physicians and doctors of philosophy from universities and well-known health care organizations. There was no mention of who maintains the information in the site or who is responsible for the quality, accuracy, and reliability of the information provided. 


\section{Critical Evaluation of Web Sites: An Example in Osteoporosis}

The introduction to the guideline states that the information provided was evaluated by an expert panel assembled by the NOF: The members of the panel were listed, as were the reviewers of the guideline. We assume that the backgrounds and training of these individuals is appropriate for their contribution; a link to their past publications or a description of their qualifications would have better supported the validity of the guidelines. There were no direct links or contact information for these individuals.

Currency of information. Much of the information contained in this site was general information about osteoporosis, methods of prevention, and options for treatment. It was stated that the guidelines provide the "most up-to-date medical information" on osteoporosis. In light of this claim, the developers of the site failed to provide information on the frequency of updates to the site and, specifically, the reevaluation of recommendations made in the guidelines. Without this information, it is impossible to comment on the currency of the information. Cost figures reported on the site were out of date, dating to 1.995; the most current "Cutting Edge Report" was added in July 1999.

Authority of source. We assume that NOF is a reputable source of information. The organization is well known, has a positive reputation, and is considered credible and trustworthy. Its nonprofit structure adds credibility. However, it would have been useful had the site referenced its information to allow readers 10 conduct further research.

Ease of use. The NOF Web site was easy to navigate. Icons were located at the top and bottom of the Web pages. There were, however, several links within links that did become somewhat confusing when trying to evaluate the content of the site: This site did not contain a search function, which would help the user find specific information.

Accessibility and availability. No fee was associated with the use of the NOF site and access was easily attained. The integrity of the site remained stable throughout extensive manipulation of the Web pages.

Links. With the exception of a link to Osteoporosis Reports, all internal links or e-mail addresses worked appropriately. There was a malfunction in linking to the American Medical Association Web site. Using the link to the NIH site opens a new browser window, which must be shut to return to the NOF site, which remains open underneath. The site provided a link for individuals to obtain information on Medicare coverage. There were no other external links provided by the NOF site. Most often, links were internal, and many opportunities were made available, either to go to the membership section, or to NOF's online catalog to purchase information and supplies.

Attribution and documentation. References and balanced evidence were lacking from the NOF Web site. Although it stated that the guidelines were "chiefly based on evidence from randomized, controlled clinical trials... and data were gathered from published studies," the lack of direct references substantially weakens the impact of the recommendations provided. Both health care providers and consumers seek the opportunity to make their own conclusions regarding the quality of primary research. Reproduced figures and tables were referenced, but complete source information was not always provided. The section "Osteoporosis in Men" did include a brief description of the author plus eight references. The quality of the site would be vastly improved if references were provided for the entire Web site. In addition, information on the authors of the individual sections would be helpful.

Intended audience. The intended users of the site are patients and their family members, the public, and health care professionals. Specific icons were available on the home page for patients and health care professionals. General information was intended for all audiences. There were many disclaimers within the site, including the statement that "the recommendations developed are intended to serve as a reference point for clinical decision making with individual patients." Users of the site were urged to consult current prescribing information on any drug, device, or procedure discussed in the site. The site's information was appropriate for the intended users in most respects. Its major shortcomings revolved around the lack of detail provided for use by health care professionals. Although health care providers do seek general information, most often it is the detailed scientific information that they need most.

Contact addresses or feedback mechanism. Links to various e-mail addresses were present throughout the NOF. site. Email could be sent directly to the Patient Information and Education Department, the support group at NOF, and regional NOF offices. There also were instructions on obtaining the NIH ORBD NRC's information on bone fragility and prevention of falls. There was no specific feedback form for directed comments on the content of the Web site.

User support. There was no Help function available in the NOF Web site. It did, however, have a link to report problems with the site (webmaster@nof.org).

\section{Evaluation 2: National Institutes of Health Osteoporosis and Related Bone Diseases National Research Center}

Content of site. The NIH ORBD NRC Web site (www.osteo.org) was established to expand awareness and enhance knowledge and understanding of the prevention, early detection, and treatment of osteoporosis and related bone diseases. The mission, as stated on the site, is to provide patients, health professionals, and the public with an important link to resources and information on metabolic bone diseases, including osteoporosis, Paget's disease of the bone, osteogenesis imperfecta, and hyperparathyroidism. The site contained mostly general information about osteoporosis and related bone diseases. It also provided basic information about medication therapy. We focused on evaluation of the osteoporosis sections. 
The general information on osteoporosis did coincide with the information provided by the NOF site and was assumed to be accurate; however, no references were cited in these sections. The site provided a "Fast Facts" section and a more detailed "Overview of Osteoporosis." It gave a good review outlining differences between rheumatoid arthritis, osteoarthritis, and osteoporosis. In addition, the NIH ORBD NRC site gave interesting supplemental information on subjects related to osteoporosis such as lactose intolerance, gastrointestinal disorders influencing bone health, oral manifestations of bone loss, and related pregnancy and lactation issues.

Four newsletters were accessible from this site: the March, June, August, and December 1999 issues. The newsletters focus on research, prevention, the latest scientific findings, and other areas of interest. The December 1999 issue included "Research Updates" that contained a few abstracts from the literature. This was a positive attribute of the section; however, the sources listed as "updates" were not current for March 2000, nor were they all-inclusive. There was no information to describe how these particular articles were chosen or when the next newsletter would be available. An opportunity to be added to the newsletter distribution list was provided.

Several internal links provided information pertinent to specific groups (e.g., Asian women, African-American women, Latino women, men with osteoporosis). A "What's New" section contained information on new pamphlets/literature available for purchase, press releases, and upcoming events and programs. An option to be notified via e-mail when new products become available was offered.

The "Research Bibliographies" section on subjects related to metabolic bone diseases included citation and abstract information from various journals. The addition of this section to the site enhanced its quality and reliability by offering the opportunity to evaluate outside source information.

Overall, the information contained in the NIH ORBD NRC site appeared to be of good quality. There were no major discrepancies throughout this site or in comparison to the NOF site. The site provided accurate information to the best of our knowledge. With the possible exception of the bibliography section, the information contained was free of technical language and was directed mostly toward patients.

Design and aesthetics. The design and layout of this Web site was of good quality. It was well organized throughout and had a pleasing appearance.

Disclosure of authors, sponsors, developers. The NIH ORBD NRC was established in 1994 with a four-year grant awarded to the NOF from the National Institute of Arthritis and Musculoskeletal Diseases (NIAMS) of the NIH. Currently, the Web site is supported by a five-year extension of this grant with contributions from the National Institutes of Dental and Craniofacial Research and of Child Health and Human Development. The center is operated by the NOF in collabora- tion with the nonprofit Paget and Osteogenesis Foundations.

We can assume that this site was a collaborative effort of the members of the organizations listed above. The site failed to identify, however, specific authors for each section and did not reveal who was responsible for the accuracy or currency of the information provided.

Currency of information. Each section of the NiH ORBD NRC site and each resource bibliography did contain information on when it was last revised or updated; however, there were no time frames for revision identified. The disclosure information stated that the bibliographies are to be updated "regularly" and that new bibliographies will be developed as topics are identified. Several of the sections had not been updated for a significant period of time. For example, discussion sections on osteoporosis in women of different cultures hadn't been updated since 1998. In some instances, much of the information may not have changed; however, all information should be reviewed on a more frequent basis. Many of the references in the bibliography sections dated back to 1997. This led us to believe that the information contained throughout the bibliographies may not be entirely up to date. We recommend that a Medline or other search for current information be conducted instead of relying on the references provided in this site.

Authority of source. Although the information in this Web site is not directly referenced, the NIH can be considered a credible and trustworthy source of information. The NIH is one of eight health agencies of the Public Health Service, which in turn is part of the U.S. Department of Health and Human Services. In addition to the reputation of the NIH, the NOF also is considered a reputable and trustworthy organization.

Ease of use. This site was easy to navigate. Icons for all major sections were located at the top and bottom of each Web page, allowing for easy navigation between sections. The NIH site had a search mechanism, which helps the user to quickly locate specific information.

Accessibility and availability. We did not encounter any problems using the NIH ORBD NRC Web site. The site was easy to access and there were no lees charged for its use. Stability of the site was not an issue.

Links. Many quality links were included in this site. The general NIH Web site link was available as was the NOF site designated as containing more information on specific topics in osteoporosis. The section "Bone Links" offered direct access to other national and international organizations related to diseases of the bone, nutrition, and rare diseases. A link to the U.S. National Library of Medicine was also included. This link was of particular help because it allows direct access to Medline. Several links for information on preventing falls were listed on the "Clinician's Page." A link back to the NOF's Clinical Guidelines for Professionals was also present.

Descriptions of database services provided by the $\mathrm{NIH}$ ORBD NRC organization included "BoneData," an in-house 
database that serves as a resource for responding to information requests received by NIH ORBD NRC. It was said to contain references 10 brochures, books, book chapters, fact sheets, organizations, and programs on prevention, diagnosis, treatment, and coping strategies for osteoporosis and related bone diseases. The Resource Center has also developed the Cumulative Index to Metabolic Bone Diseases Literature database. These databases are intended to contain the latest clinical research and seminal studies on relevant topics, but were not available directly through this site, although contact information was provided. It would have been useful to have access to this information if it was more up-to-date than the research bibliographies provided in the site. There was also a link to the National Osteoporosis Data Group (NODG) bibliography.

Links for upcoming events and programs were also available. Through these links, registration information for conferences and meetings was provided. Overall, the links available through the NIH site were very useful and applicable.

Attribution and documentation. There were inconsistencies in the presentation of references. Some sections contained specific citations, while others did not. The NODG bibliography, said to provide the "most relevant and authoritative published data on the central issues of osteoporosis," included citations and abstracts from 134 seminal studies and significant papers from 1965 to 1997 . Several important articles that have been published since 1.997 , were absent from this source.

Several annotated bibliographies were available through this site. The vast majority of articles relerenced were written before 1998. Again, no authors of these annotated bibliographies were revealed. Medline was listed as a source for obtaining information contained in the site.

Overall, the NIH site did provide multiple references to support its information; however, many of the articles were out of date, making the claim that the bibliographies are regularly updated seem less reliable. The general information section lacked cited references. It was our opinion that the bibliographies, although helpful, gave a false sense of providing the most current information. It would have been prudent to include a disclaimer directly addressing this issue on the Research Bibliographies main page. The NIH ORBD NRC could then direct practitioners to Medline for up-to-date information.

Intended audience. The intended audience includes health care professionals, patients, and the general public. Most areas of the site are appropriate for use by all three groups. The Research Bibliographies may be more suited for evaluation by health care providers.

Contact addresses or feedback mechanism. This site did offer a specific form for leedback that could be completed and submitted online. In addition, the NIH ORBD NRC Customer Service Policy described how to contact the organization, with a promise of a timely response. Address, phone, and e-mail contact information for the organization was readily available throughout most sections.

User support. There was no specific Help function available in this site, nor was there a support mechanism in place for online users.

\section{Evaluation 3: Doctor's Guide to Osteoporosis Information and Resources}

Content of site. The "Current Content" of this site (www.pslgroup.com/OSTEOPOROSIS.htm) listed the following sections: "Medical News and Alerts," "Osteoporosis Information," "Discussion Groups and Newsgroups," "Other Related Sites," and "Stay Abreast of Osteoporosis Developments on the Internet." The quality of this site relies heavily on the many sites to which it provides links for specific information. This site was more commercial than the NOF and NIH ORBD NRC Web sites previously evaluated, having for-profit sponsors and advertisers. This site primarily exists to provide links to sites such as the NOF, the Foundation for Osteoporosis Research and Education (FORE), the NIH ORBD NRC, and the Mayo Clinic Health Oasis Web pages. When evaluating this type of site, Internet users must first evaluate the quality, accuracy, and reliability of the sources it draws its information from.

Design and aesthetics. The Doctor's Guide site was well designed for the purpose that it serves. Headings are underlined and links reached by clicking on the highlighted text.

Disclosure of authors, sponsors, developers. This site was developed by the P/S/L Consulting Group, Inc., which describes itself as an organization "dedicated to providing the information and information services, most likely to help promote the informed and appropriate use of medicines by health care professionals and organizations as well as by the people to whom they are prescribed." There was no reference to what "P/S/L" stands for other than that it is a medical communications and research group based in Canada. The only information provided on the consulting group itself was a link to the $\mathrm{P} / \mathrm{S} / \mathrm{L}$ e-mail directory.

Several sponsors support the operation of this site. More than 30 organizations worldwide, most pharmaceutical companies, were listed. The group had a disclaimer posted under a "Warning!" icon stating that "P/S/L does not endorse any of the medications, products, or treatments described, mentioned, or discussed in any of the services, databases, or pages accessible within or from the Doctor's Guide, Doctor's Exchange, or any other $\mathrm{P} / \mathrm{S} / \mathrm{L}$ service or publication." This site should be used on a "reader beware" basis. Much of the information provided is advertising from the pharmaceutical companies and must be cautiously evaluated.

The Doctor's Guide site made reference to its advisory board but did not identify any members. In fact, there was an advertisement recruiting interested individuals to apply for a spot on an advisory board. It was not clearly stated whether this site, specifically, is for-profit or not-for-profit. 


\section{TABLE 1 Key Strengths and Weaknesses of the Three Web Sites Reviewed}

\begin{tabular}{|c|c|c|}
\hline Site & Key Strengths & Key Weaknesses \\
\hline $\begin{array}{l}\text { National Osteoporosis } \\
\text { Foundation (NOF) } \\
\text { www.nof.org }\end{array}$ & $\begin{array}{l}\text { - Easy to understand and access } \\
\text { - Good overview } \\
\text { - Advocacy section } \\
\text { - Reputation of NOF }\end{array}$ & $\begin{array}{l}\text { - Lack of details for health care providers } \\
\text { - Lack of references } \\
\text { - No information regarding updates } \\
\text { to information } \\
\text { - No specific authors identified }\end{array}$ \\
\hline $\begin{array}{l}\text { National Institutes of Health } \\
\text { Osteoporosis and Related Bone } \\
\text { Diseases-National Research } \\
\text { Center (NIH ORBD NRC) } \\
\text { www.osteo.org }\end{array}$ & $\begin{array}{l}\text { - Reference section provided } \\
\text { - Easy to understand/access } \\
\text { - Good overview } \\
\text { - Reputation of NIH }\end{array}$ & $\begin{array}{l}\text { - Lack of details for health care providers } \\
\text { - References not up to date (most before 1997) } \\
\text { - Inconsistent updates of information in site } \\
\text { - No specific authors identified }\end{array}$ \\
\hline $\begin{array}{l}\text { Doctor's Guide to } \\
\text { Osteoporosis Information and Resources } \\
\text { www.pslgroup.com.OSTEOPOROSIS.htm }\end{array}$ & $\begin{array}{l}\text { - Current news articles highlighted } \\
\text { - Easily accessible } \\
\text { - Several links supplied }\end{array}$ & $\begin{array}{l}\text { - Lack of references } \\
\text { - Relies almost entirely on information from } \\
\text { alternative sites } \\
\text { - Lack of revealed authorship/support }\end{array}$ \\
\hline
\end{tabular}

Currency of information. There was no specific information identifying how often this site is updated. At the time of this evaluation, "Medical News and Alerts" did have articles listed as recent as March 7, 2000. The articles in this section were listed in chronological order beginning with the most recent. All updates for the general information provided by the outside links would depend on the updates provided by each of those contributing organizations. No information was provided on the maintenance of this site.

Authority of source. There was no sure way to evaluate the reputation, credibility, or trustworthiness of the P/S/L Group. There was no explanation or rationale describing the process by which sponsors and/or "information sites" were chosen. Some of the articles referenced in the "Medical News and Alerts" section are from reputable journals, such as the Journal of the American Medical Association and the New England Journal of Medicine. These articles are summarized and interpreted by an unknown source, however, and the actual journal abstracts are not included. Many of the articles in this section are summaries of posters or presentations and have only links to the pharmaceutical companies that sponsored them. Again, it is important that the reader use judgment in examining and interpreting the information contained in this site. We strongly encourage patients and other consumers to be very cautious when reviewing information on the Doctor's Guide site. Individuals should seek the advice of their physician if questions or concerns arise.

Ease of use. The Doctor's Guide site was easy to use. Icons at both the top and bottom of the page allowed for easy navigation. A helpful search function was available.

Accessibility and availability. The Doctor's Guide site was easy to access. There were no apparent fees to the consumer, and there were no problems with the stability of the site.
Links. Links were a major component of this site. As stated earlier, the NOF, NIH ORBD NRC, FORE, and Mayo Clinic Web pages were linked to this site. A section called "Discussion Groups and Newsgroups" was available and appeared to be either e-mail or chat-room links; however, we were unable to gain access to these links and were instructed to contact the server for more information. There were also several links to the sponsors of the site-mainly pharmaceutical companies. The section on "Other Related Sites" was disappointing. One link was nonfunctional and had been so since 1998, which again drew into question the frequency with which this site is updated. There were also problems returning from some of these links back to the Doctor's Guide site. Most of the sites provided some additional general information.

Attribution and documentation. The Doctor's Guide site did not provide specific references unique to its own information. In most instances, though, the information was obtained from other sites. The main function of this site was to compile the information available from other sources in an effort to decrease the time it takes for providers to locate the information. When direct reference was made to a journal article, the site sometimes provided a direct link to that journal but not specifically to the article being discussed.

Intended audience. As implied in the name, the Doctor's Guide was intended for physicians; however, the heading on the "Osteoporosis Information \& Resources" page stated that the site provides the "latest medical news and information for patients or friends/parents of patients diagnosed with osteoporosis and osteoporosis-related disorders." Interestingly, there was no mention of physicians in this particular site except on the main P/S/L Consulting Group Web page. The information contained in this site may be useful to health care professionals 
as a starting point in searching for information on osteoporosis. This would be especially true if current, news-breaking articles are highlighted on an ongoing basis. Use by patients, consumers, and the general public may pose a slightly. greater risk for misinterpretation because of the need to critically evaluate the information provided

Contact information or feedback mechanism. An icon was available to be added to the P/S/L Consulting Group's email notification list. The Directory on P/S/L's main page offered e-mail access to individuals, but did not reveal who these individuals were or their positions

User support. There was no help function provided in this Web site; however, technical questions or other concerns about the site were directed to webmaster@pslgroup.com.

\section{Discussion}

Overall, the three Web sites evaluated in this article provided some general information that might be useful to health care providers (see Table 1). All sites were easy to access and navigate. Consistently, each site was weak in providing adequate referencing, which is an extremely important factor to health care providers seeking information on the Internet. The NOF and NIH ORBD NRC sites were similar because they are both operated by the NOF. These sites are supported by a national organization and a government agency. In contrast, the Doctor's Guide Web site is sponsored by the P/S/L Consulting Group, whose authority was not adequately documented anywhere in the Web site.

\section{Conclusion}

It is extremely important that Web sites focused on providing health-related information be critically evaluated. The 1.2 core areas for evaluation were helpful and easy to follow. Several shortcomings of each Web site considered were identified, as were their strengths. The quality, reliability, and accountability of Web sites containing health information must be held to the highest of standards. The time spent assessing the quality of Internet sources used in formulating ideas, opinions, and understanding of health topics is essential. As the Internet continues to grow, so must the integrity of the information it provides.

\section{References}

1. Nielsen NetRatings. Internet usage statistics for the month of February 2000 http://209.249.142.16/nnpm/owa/Nrpublicreports.usagemonthly. Accessed March 2000

2. Elliott B, Elliot G. High volume medical Web sites. Delaware Med J 2000; 72 (1): $21-29$.

3. Hatfield CL, May SK, Markoff JS. Quality of consumer drug information provided by four Web sites. Am J Health-Syst Pharm 1999; 56: 2308-11.

4. Kim P, et al. Published criteria for evaluating health related Web sites: review. BMJ 1999; 318: 647-49.

5. Yahoo, www.yahoo.com. Accessed February 2000

6. WebMDHealth, www.my.webmd.com. Accessed February 2000.

7. National Osteoporosis Foundation, www.nof.org. Accessed March 2000

8. National Institutes of Health Osteoporosis and Related Bone Diseases National Resource Center, www.osteo.org. Accessed March 2000.

9. P/S/L Consulting Group, Inc., www.pslgroup.com/osteoporosis.htm. Accessed March 2000. 
Upon completion of this article, the successful participant should be able to:

1. Discuss 12 criteria by which to evaluate health-related Web sites.

2. Discuss the quality of three Web sites related to osteoporosis based on these criteria.

3. Define the health care provider's role and responsibility in making recommendations based on Internet information.

4. More critically evaluate health-related Web sites in practice.

\section{SELF-ASSESSMENT QUESTIONS}

1. Which of the following statements is TRUE?

a. There are more than 122 million Internet users in the United States alone.

b. The use of medical information from the World Wide Web is on the decline.

c. The number of Web users looking for medical information is predicted to rise to over 30 million in 2000 .

d. A and $C$ are true.

2. Which of the following include criteria recommended for evaluating a Web site?
a. content of the site and detailed references
b. ease of use and accessibility
c. authority of source
d. disclosure of authors and sponsors
e. all of the above

\section{The Doctor's Guide to Osteoporosis} Information and Resources was:

\section{a. supported by a grant from the} National Institutes of Health.

b. a thorough evaluation of osteoporosis best suited for use by physicians.

c. a source that highlighted some current news articles.

d. all of the above.
4. The National Osteoporosis

Foundation (NOF) Web site:
a. provides an "Advocacy" section that offers information on getting involved in legislative issues related to osteoporosis.
b. provides Clinical Guidelines for the treatment of osteoporosis.
c. provides a detailed reference section to support all information contained in the site.
d. A and B.

5. All three sites evaluated in this review appropriately identified authorship for sections within their Web site.
a. True
b. False

6. The area most stressed in evaluating these health-related Web sites was:
a. use of color and design of the Web page.
b. link to a Webmaster.
c. availability of a specific feedback form.
d. inclusion (or lack) of references.

7. The National Institutes of Health

Osteoporosis and Related Bone

Diseases National Research Center

(NHH ORBD NRC) Web site excelled

in which of the following areas com-

pared with both the NOF and

Doctor's Guide Web sites:
a. It provided the best overview of osteoporosis.

b. It contained a resource bibliography.

c. All of its references were up to date as of March 2000

d. It was easiest to navigate.

8. The Doctor's Guide to Osteoporosis Information and Resources:

a. relied entirely on outside information sources and links.

b. was developed by the P/S/L

Consulting Group, Inc. c. is sponsored by several pharmaceutical companies.

d. All of the above.

9. Areas that were consistently lacking in each of the three sites included:
a. ease of accessibility.
b. adequate information on the frequency of updates to each site.
c. complete, up-to-date references.
d. B and C.

10. When evaluating health-related Web sites, practitioners should:
a. cautiously examine the information presented.

b. consider using the 1.2 criteria published by Kim et al. to evaluate the site.

c. pay particular attention to references and supportive documentation of information provided.

d. refer to other sources of information such as Medline and other primary literature resources to support recommendations.

e. all of the above. 


\section{DEMOGRAPHIC INFORMATION (not for scoring)}

11. In what type of setting do you work? (Leave blank if none of the responses below applies.)
a. $\mathrm{HMO}$
b. PPO
c. Indemnity insurance
d. Pharmacy benefits management
c. Other

12. Did this program achieve its educational objectives?
a. Yes
b. No

13. How many minutes did it take you to complete this program, including the quiz? (Fill in on answer sheet.)
14. Did this program provide insights relevant or practical for you or your work?
a. Yes
b. No

15. Please rate the quality of this CE article.
a. Excellent
c. Fair
b. Good
d. Poor

\section{INSTRUCTIONS}

$\mathrm{AE}$ This test affords 1 hour ( $0.10 \mathrm{CEU})$ of continuing pharmaceutical education in all states that recognize the American Council on Pharmaceutical Education. To receive credit, you must score at least $70 \%$ of your test answers correctly. To record an answer, darken the appropriate block below. Mail your completed answer sheet to: Academy of Managed Care Pharmacy, 100 N. Pitt Street, Suite 400 , Alexandria, VA 22314. If you score $70 \%$ or more, a certificate of achievement will be mailed to you within six to eight weeks. If you fail to achieve $70 \%$ on your first try, you will be allowed only one retake. The ACPE Provider Number for this lesson is 233-000-00-004-H04. This offer of continuing education credits expires August 31, 2001.
\begin{tabular}{lllll} 
A & B & C & D & E \\
\hline
\end{tabular}
\begin{tabular}{lllll}
$\mathrm{A}$ & $\mathrm{B}$ & $\mathrm{C}$ & $\mathrm{D}$ & $\mathrm{E}$ \\
\hline
\end{tabular}
1. $\square \quad \square \quad \square \quad \square \quad \square$
6. $\square \quad \square \quad \square \quad \square \quad \square$
2. $\square コ 一 ⿻ 上 丨$
7. $\square$ ○
3. $\square \quad \square \quad \square \quad \square \quad \square$

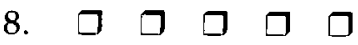

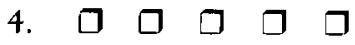
9. $\square \quad \square \quad \square \quad \square \quad \square$
5. $\square$ ๑
10.
$\square \quad \square \quad \square \quad \square \quad \square$

11. $\square \mathrm{A} \square \mathrm{B} \quad \square \mathrm{C} \quad \square \mathrm{D} \quad \square \mathrm{E}$

12. $\square$ Yes $\square \mathrm{No}_{\mathrm{O}}$

13. Minutes

14. $\square$ Yes $\square$ No

15. $\square A \quad \square B \quad \square C \quad \square D$

Participant Identification: Please type or print.

Date:

Social Security \#:

For Identification Purposes Only

Work Phone \#:

Name:

LAST FIRST MIDDLE

Company:

Address:

\begin{tabular}{llll}
\hline STREET (with Ap. No.) or P.O. Box & CITY & STATE & ZIP
\end{tabular}

State \& Lic. No.:

STATE LICENSE NO.

Member Type: $\square$ Aclive $\square$ Supporting Associate . $\square$ Student $\square$ Nonmember 